Pacific Journal of Mathematic 


\title{
BEST APPROXIMATION BY A SATURATION CLASS OF POLYNOMIAL OPERATORS
}

\author{
D. S. Goel, A. S. B. Holland, \\ C. NASIM, AND B. N. SAHNeY
}

The problem of determining a saturation class has been considered by Zamanski, Sunouchi and Watari and others. Zamanski has considered the Cesaro means of order 1 and Sunouchi and Watari have studied the Riesz means of type $n$. The object of the present paper is to extend these results by considering Nörlund means which include the above-mentioned results as particular cases.

1. Let $\left\{p_{n}\right\}$ be a sequence of positive constants such that

$$
P_{n}=p_{0}+\cdots+p_{n} \longrightarrow \infty \text { as } n \longrightarrow \infty \text {. }
$$

A given series $\sum_{n=0}^{\infty} d_{n}$ with the sequence of partial sums $\left\{S_{n}\right\}$ is said to summable $\left(N, p_{n}\right)$ to $d$, provided that

$$
\begin{aligned}
N_{n}\left[\sum_{l=0}^{\infty} d_{l}\right] & =\frac{1}{P_{n}} \sum_{k=0}^{n} P_{n-k} d_{k} \\
= & \frac{1}{P_{n}} \sum_{k=0}^{n} p_{n-k} S_{k} \longrightarrow d, \text { as } n \longrightarrow \infty,
\end{aligned}
$$

and $N_{n}$ are called the Nörlund operators.

Let

$$
\frac{1}{2} a_{0}+\sum_{k=1}^{\infty}\left(a_{k} \cos k x+b_{k} \sin k x\right) \equiv \sum_{k=0}^{\infty} A_{k}(x)
$$

be the Fourier series associated with a continuous periodic function $f(x)$, with period $2 \pi$.

We define

$$
N_{n}(x) \equiv N_{n}(f ; x) \equiv \frac{1}{P_{n}} \sum_{k=0}^{n} P_{n-k} A_{k}(x)
$$

and the norm

$$
\left\|f(x)-N_{n}(x)\right\| \equiv \max _{0 \leqq x \leqq 2 \pi}\left|f(x)-N_{n}(x)\right| .
$$

If there exists positive nonincreasing function $\phi(n)$ and a class of functions $K$, with the following properties:

(I) $\left\|f(x)-N_{n}(x)\right\|=o(\phi(n)) \Longrightarrow f(x)$ is constant,

(II) $\left\|f(x)-N_{n}(x)\right\|=O(\phi(n)) \Longrightarrow f(x) \in K$ 
and

(III) $f(x) \in K \Longrightarrow\left\|f(x)-N_{n}(x)\right\|=O(\phi(n))$,

then the Nörlund operators are saturated with the order $\phi(n)$ and the class $K$.

In this paper we prove that the above method of summations is saturated with the order $p_{n} / P_{n}$ and that the class $K$ consists of all continuous functions $f$ such that $\tilde{f} \in \operatorname{Lip} 1$, where $\tilde{f}$ is the conjugate function of $f$. By definition

$$
\widetilde{f}(x)=\frac{1}{2 \pi} \int_{0}^{\pi}[f(x+t)-f(x-t)] \cot \frac{1}{2} t d t,
$$

if the integral converges absolutely for all $x$ and if

$$
\int_{0}^{\pi}|f(x+t)-f(x-t)| \cot \frac{t}{2} d t
$$

is an integrable function.

The problem of determining a saturation class by considering $(C$, 1) means of the Fourier series of $f(x)$ has been considered by Zamanski [6]. Sunouchi and Watari [4] have considered the problem by taking $(R, \lambda, k)$ means of the Fourier series. Some of these results were later extended by Sunouchi [3] and others [2,5].

\section{We shall prove the following theorem.}

THEOREM. Let $\left\{p_{n}\right\}$ be a sequence of positive constants satisfying the following conditions,

$$
\frac{p_{n-k}}{p_{n}} \longrightarrow 1 \text { as } n \longrightarrow \infty \text { for a fixed } k \leqq n,
$$

and

$$
\sum_{k=0}^{n}\left|p_{n-k}-p_{n-k-1}\right|=O\left(p_{n}\right) \text { where }\left[p_{-1}=0\right] .
$$

Then the operators $N_{n}$ are saturated with order $p_{n} / P_{n}$ and the class of all continuous functions f for which $\tilde{f} \in L i p 1$.

The following lemmas are required for the proof of the theorem.

LEMMA 2.1. If

$$
\left\|f(x)-N_{n}(x)\right\|=o\left[\frac{p_{n}}{P_{n}}\right]
$$

then $f$ is a constant. 
Proof. From (1.3) we obtain

$$
\begin{aligned}
\frac{1}{\pi} \int_{-\pi}^{\pi} & N_{n}(x) \cos r x d x=\frac{1}{\pi} \int_{-\pi}^{\pi} \sum_{k=0}^{n} \frac{P_{n-k}}{P_{n}} A_{k}(x) \cos r x d x \\
= & \frac{1}{\pi} \sum_{k=0}^{n} \frac{P_{n-k}}{P_{n}} \int_{-\pi}^{\pi} A_{k}(x) \cos r x d x \\
& =\frac{P_{n-r}}{P_{n}} a_{r} .
\end{aligned}
$$

Thus,

$$
\begin{aligned}
a_{r}-\frac{P_{n-r}}{P_{n}} a_{r} & =\frac{1}{\pi} \int_{-\pi}^{\pi} f(x) \cos r x d x-\frac{1}{\pi} \int_{-\pi}^{\pi} N_{n}(x) \cos r x d x \\
& =\frac{1}{\pi} \int_{-\pi}^{\pi} \cos r x\left[f(x)-N_{n}(x)\right] d x,
\end{aligned}
$$

hence

$$
\left|a_{r}-\frac{P_{n-r}}{P_{n}} a_{r}\right| \leqq\left\|f(x)-N_{n}(x)\right\| \frac{1}{\pi} \int_{-\pi}^{\pi} 1 \cdot d x=0\left[\frac{p_{n}}{P_{n}}\right] .
$$

Consequently

$$
a_{r}\left\{\frac{p_{n}+\cdots+p_{n-r+1}}{p_{n}}\right\}=o(1),
$$

and since $p_{r}>0$ for all $r$, we have $\left(p_{n}+\cdots+p_{n-r+1}\right) / p_{n} \geqq 1$ for $r \geqq 1$.

Thus from (2.3) it follows that $a_{r}=0$, for each $r \geqq 1$. Similarly we can show that $b_{r}=0$ for each $r \geqq 1$. Hence $f(x)=1 / 2 a_{0}$, a constant.

LEMMA 2.2. If

$$
\left\|f(x)-N_{n}(x)\right\|=O\left[\frac{p_{n}}{P_{n}}\right]
$$

and condition (2.1) is satisfied, then $\tilde{f}(x) \in \operatorname{Lip} 1$.

Proof. It can be shown without much difficulty that if

$$
\left\|f(x)-N_{n}(x)\right\|=O\left[\frac{p_{n}}{P_{n}}\right],
$$

then

$$
\left\|\sum_{k=1}^{N} \frac{p_{n}+\cdots+p_{n-k+1}}{p_{n}} A_{k}(x)\left[1-\frac{k}{N+1}\right]\right\|=O(1), N \leqq n .
$$

Taking the limit as $n \longrightarrow \infty$, and using condition (2.1), we obtain 


$$
\left\|\sum_{k=1}^{N} k A_{k}(x)\left[1-\frac{k}{N+1}\right]\right\|=O(1) .
$$

The left hand side of the above equation represents the $(C, 1)$ mean of the series

$$
\sum_{k=1}^{\infty}-k A_{k}(x)
$$

Since $-k A_{k}(x)=B_{k}^{\prime}(x)$, where $\sum_{k=1}^{\infty} B_{k}(x) \equiv \sum_{k=1}^{\infty}\left(b_{k} \cos k x-\alpha_{k} \sin k x\right)$ is the conjugate series of (1.2), then (2.4) is equivalent to

$$
\left\|\widetilde{\sigma}_{N}^{\prime}(f)\right\|<M
$$

which implies that $\widetilde{f}(x) \in \operatorname{Lip} 1,[1]$.

$\left(\tilde{\sigma}_{N}(f)\right.$ represents the $(C, 1)$ mean of the conjugate series.)

LEMma 2.3. Assume $\tilde{f} \in \operatorname{Lip} 1$. If the sequence $\left\{p_{n}\right\}$ satisfies condition (2.2), then

$$
\left\|f(x)-N_{n}(x)\right\|=O\left[\frac{p_{n}}{P_{n}}\right] .
$$

Proof. Since, by definition

$$
\widetilde{S}_{n}(\tilde{f}, x)=\frac{1}{\pi} \int_{0}^{\pi}[\tilde{f}(x, t)-\tilde{f}(x-t)] \frac{\cos \frac{t}{2}-\cos \left[n+\frac{1}{2}\right] t}{2 \sin \frac{t}{2}} d t
$$

where $\widetilde{S}_{n}(\tilde{f}, x)$ denotes the partial sums of the conjugate series associated with $\tilde{f}(x)$, we have

$$
\begin{aligned}
& N_{n}\left(\widetilde{S}_{n}(\tilde{f}, x)\right)=\frac{1}{P_{n}} \sum_{k=0}^{n} p_{n-k} \widetilde{S}_{k}(\tilde{f}, x) \\
& =\frac{1}{P_{n}} \sum_{k=0}^{n} p_{n-k} \frac{1}{2 \pi} \int_{0}^{\pi}[\tilde{f}(x+t)-\tilde{f}(x-t)] \cot \frac{1}{2} t d t \\
& \quad-\frac{1}{P_{n}} \sum_{k=0}^{n} p_{n-k} \frac{1}{2 \pi} \int_{0}^{\pi}[\tilde{f}(x+t)-\tilde{f}(x-t)] \frac{\cos \left[k+\frac{1}{2}\right] t}{\sin \frac{1}{2} t} d t .
\end{aligned}
$$

Since the function $\widetilde{f}(x) \in \operatorname{Lip} 1,-f+(1 / 2) a_{0}$ is identical to $\tilde{\tilde{f}}$, therefore

$$
f(x)-N_{n}(f, x)=\frac{1}{2 \pi} \int_{0}^{\pi}[\widetilde{f}(x+t)-\tilde{f}(x-t)] K_{n}(t) d t,
$$

where 


$$
K_{n}(t)=\frac{1}{P_{n} \sin \frac{1}{2} t} \sum_{k=0}^{n} p_{n-k} \cos \left[k+\frac{1}{2}\right] t .
$$

Now by partial summation

$$
\begin{aligned}
K_{n}(t) & =\frac{1}{2 P_{n} \sin ^{2} \frac{1}{2} t} \sum_{k=0}^{n}\left(p_{n-k}-p_{n-k-1}\right) \sin (k+1) t \\
& =\frac{1}{P_{n}}\left\{\frac{2}{t^{2}}+O(1)\right\} \sum_{k=0}^{n}\left(p_{n-k}-p_{n-k-1}\right) \sin (k+1) t \\
& =\frac{2}{P_{n} t^{2}} \sum_{k=0}^{n}\left(p_{n-k}-p_{n-k-1}\right) \sin (k+1) t+O\left[\frac{p_{n}}{P_{n}}\right],
\end{aligned}
$$

by hypothesis. Since $\widetilde{f}(x)$ is certainly bounded, the right hand side of (2.5) becomes

$$
\begin{aligned}
& \frac{1}{\pi P_{n}} \int_{0}^{\pi}[\widetilde{f}(x+t)-\widetilde{f}(x-t)] \frac{1}{t^{2}}\left\{\sum_{k=0}^{n}\left(p_{n-k}-p_{n-k-1}\right) \sin (k+1) t\right\} d t \\
& \quad+O\left[\frac{p_{n}}{P_{n}}\right] .
\end{aligned}
$$

Let us write

$$
F_{n}(t)=\frac{1}{P_{n}} \int_{t}^{\pi} \frac{1}{u^{2}}\left\{\sum_{k=0}^{n}\left(p_{n-k}-p_{n-k-1}\right) \sin (k+1) u\right\} d u .
$$

Since $\tilde{f}(u) \in \operatorname{Lip} 1$, it is an indefinite integral of a bounded function, say $\tilde{f}^{\prime}(u)$. Further, since $\tilde{f}(x+t)-\tilde{f}(x-t)=O(t)$, as $t \rightarrow 0$, while for fixed $n, F_{n}(t)=O(\log (1 / t))$, we can integrate (2.6) by parts to obtain

$$
\frac{1}{\pi} \int_{0}^{\pi}\left[\tilde{f}^{\prime}(x+t)+\tilde{f}^{\prime}(x-t)\right] F_{n}(t) d t+O\left[\frac{p_{n}}{P_{n}}\right],
$$

noting that the integrated term vanishes at both limits. The absolute value of this above expression is now,

$$
O\left\{\int_{0}^{\pi}\left|F_{n}(t)\right| d t\right\}+O\left[\frac{p_{n}}{P_{n}}\right] \text { since } \widetilde{f}^{\prime} \text { is bounded . }
$$

Now

$$
\begin{aligned}
F_{n}(t) & =\frac{1}{P_{n}} \sum_{k=0}^{n}\left(p_{n-k}-p_{n-k-1}\right) \int_{t}^{\pi} \frac{\sin (k+1) u}{u^{2}} d u \\
& =\frac{1}{P_{n}} \sum_{k=0}^{n}\left(p_{n-k}-p_{n-k-1}\right)(k+1) \int_{(k+1) t}^{(k+1) \pi} \frac{\sin \nu}{\nu^{2}} d \nu
\end{aligned}
$$

However, 


$$
\int_{(k+1) t}^{(k+1) \pi} \frac{\sin \nu}{\nu^{2}} d v=\left\{\begin{array}{lll}
O(\log 1 /(k+1) t) & \text { if } & (k+1) t<1 \\
O\left(1 /(k+1)^{2} t^{2}\right) & \text { if } & (1(k+1) t \geqq 1
\end{array}\right.
$$

Hence

$$
\begin{aligned}
\int_{0}^{\pi}\left|F_{n}(t)\right| d t= & O\left\{\frac { 1 } { P _ { n } } \int _ { 0 } ^ { \pi } \left[\sum_{\substack{(k+1)<1 / t \\
k \geq 0}}\left|p_{n-k}-p_{n-k-1}\right|(k+1) \log (1 /(k+1) t)\right.\right. \\
& \left.+\sum_{\substack{(k+1) \geq 11 / t \\
k \leqq n}}\left|p_{n-k}-p_{n-k-1}\right| 1 /(k+1) t^{2}\right] d t \\
= & O\left\{\frac { 1 } { P _ { n } } \sum _ { k = 0 } ^ { n } | p _ { n - k } - p _ { n - k - 1 } | \left[\int_{0}^{1 /(k+1)}(k+1) \log (1 /(k+1) t) d t\right.\right. \\
& \left.\left.+\int_{1 /(k+1)}^{\pi} \frac{1}{(k+1) t^{2}} d t\right]\right\} .
\end{aligned}
$$

Further,

$$
\int_{0}^{1 /(k+1)} \log (1 /(k+1) t) d t=\int_{0}^{1} \log \left(\frac{1}{u}\right) d u=\text { constant }
$$

and

$$
\int_{1 /(k+1)}^{\pi} \frac{1}{(k+1) t^{2}} d t<M \text { (constant) }
$$

therefore

$$
\int_{0}^{\pi}\left|F_{n}(t)\right| d t=O\left\{\frac{1}{P_{n}} \sum_{k=0}^{n}\left|p_{n-k}-p_{n-k-1}\right|\right\}=O\left[\frac{p_{n}}{P_{n}}\right]
$$

from (2.2).

Thus (2.7) and hence (2.6) is $O\left[p_{n} / P_{n}\right]$. Consequently from (2.5), we have that

$$
\left\|f(x)-N_{n}(f, x)\right\|=O\left[\frac{p_{n}}{P_{n}}\right]
$$

which proves the lemma.

The proof of the theorem now follows from Lemmas 2.1, 2.2, and 2.3.

The authors wish to thank Dr. B. Kuttner of the University of Birmingham, for his very helpful suggestions.

\section{REFERENCES}

1. J. Favard, Sur la saturation des procédés de sommation, J. de Math., 36 (1957), 359-372.

2. K. Ikeno and Y. Suzuki, Some remarks of saturation problem in the local approximation, Tôhoku Math. J., 20 (1968), 214-233. 
3. G. Sunouchi, On the class of saturation in the theory of approximation I, II, III, Tôhoku Math. J., 12 (1960), 339-344; 13 (1961), 112-118; 320-328.

4. G. Sunouchi and C. Watari, On determination of the class of saturation in the theory of approximation of Functions, Proc. Japan Acad., 34 (1958), 477-481.

5. Y. Suzuki, Saturation of local approximation by linear positive operators, Tôhoku Math. J., 17 (1965), 210-221.

6. M. Zamanski, Classes de saturation de certaines procédés d'approximation des séries de Fourier des functions continues, Ann. Sci Ecole Normale Sup., 66 (1949), 19-93.

Received March 2, 1973.

The University of Calgary 



\section{PACIFIC JOURNAL OF MATHEMATICS}

EDITORS

RICHARD ARENS (Managing Editor)

University of California

Los Angeles, Calıfornia 90024

R. A. Beaumont

University of Washington

Seattle, Washington 98105
J. DugundJI

Department of Mathematics

University of Southern California

Los Angeles, California 90007

D. Gilbarg and J. Milgram

Stanford University

Stanford, California 94305

\section{ASSOCIATE EDITORS}
E. F. BECKENBACH
B. H. NeumanN
F. WOLF
K. YOSHIDA

\section{SUPPORTING INSTITUTIONS}

UNIVERSITY OF BRITISH COLUMBIA

CALIFORNIA INSTITUTE OF TECHNOLOGY

UNIVERSITY OF CALIFORNIA

MONTANA STATE UNIVERSITY

UNIVERSITY OF NEVADA

NEW MEXICO STATE UNIVERSITY

OREGON STATE UNIVERSITY

UNIVERSITY OF OREGON

OSAKA UNIVERSITY
UNIVERSITY OF SOUTHERN CALIFORNIA

STANFORD UNIVERSITY

UNIVERSITY OF TOKYO

UNIVERSITY OF UTAH

WASHINGTON STATE UNIVERSITY

UNIVERSITY OF WASHINGTON

AMERICAN MATHEMATICAL SOCIETY NAVAL WEAPONS CENTER 


\section{Pacific Journal of Mathematics}

\section{Vol. 55, No. $1 \quad$ September, 1974}

Robert Lee Anderson, Continuous spectra of a singular symmetric

differential operator on a Hilbert space of vector-valued functions . . . $\quad 1$

Michael James Cambern, The isometries of $L^{p}(X, K) \ldots \ldots \ldots \ldots \ldots . . \ldots$

R. H. Cameron and David Arne Storvick, Two related integrals over spaces of continuous functions ................................

Gary Theodore Chartrand and Albert David Polimeni, Ramsey theory and

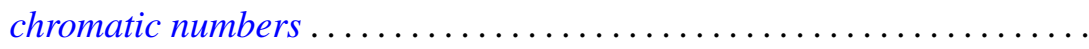

John Deryck De Pree and Harry Scott Klein, Characterization of collectively compact sets of linear operators ...................

John Deryck De Pree and Harry Scott Klein, Semi-groups and collectively compact sets of linear operators ....................... 55

George Epstein and Alfred Horn, Chain based lattices.............. 65

Paul Erdős and Ernst Gabor Straus, On the irrationality of certain series . . 85

Zdeněk Frolík, Measurable uniform spaces................... 93

Stephen Michael Gagola, Jr., Characters fully ramified over a normal

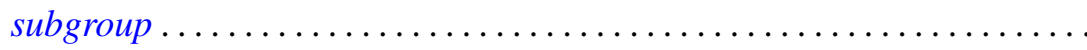

Frank Larkin Gilfeather, Operator valued roots of abelian analytic

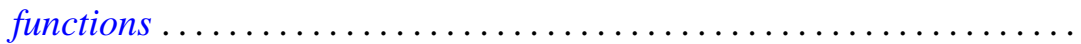

D. S. Goel, A. S. B. Holland, Cyril Nasim and B. N. Sahney, Best approximation by a saturation class of polynomial operators

James Secord Howland, Puiseux series for resonances at an embedded

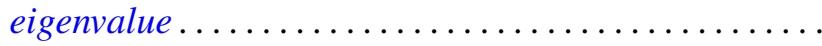

David Jacobson, Linear GCD equations .................

P. H. Karvellas, A note on compact semirings which are multiplicative

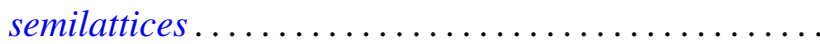

Allan Morton Krall, Stieltjes differential-boundary operators. II . .

D. G. Larman, On the inner aperture and intersections of convex sets

S. N. Mukhopadhyay, On the regularity of the $P^{n}$-integral and its application to summable trigonometric series ....... .

Dwight Webster Read, On $(J, M, m)$-extensions of Boolean algebras ....

David Francis Rearick, Multiplicativity-preserving arithmetic power series.

Indranand Sinha, Characteristic ideals in group algebras

Charles Thomas Tucker, II, Homomorphisms of Riesz spaces . . .

Kunio Yamagata, The exchange property and direct sums of indecomposable injective modules. 